\title{
Cutting force analysis in machining of titanium alloy with solid carbide cutters of different geometriy
}

\author{
Liu Jianyong, Qiao Lihong and Chen Wuyi ${ }^{a}$ \\ School of Mechanical Engineering and Automation, BeiHang University, Beijing 100191, China
}

\begin{abstract}
In order to study the cutting force in machining of titanium alloy with solid carbide cutters of different geometriy, variable helix (VH), variable pitch (VP) and standard (SD) milling cutter were used to machine titanium alloy TB6 via dry milling. The influence of cutting parameters and geometric structure parameters of milling cutters on the cutting force was investigated by the analysis of radial and tangential forces in the cutting process with three kinds of milling cutters. The experiment results showed that cutting parameters had the same influence on the radial force and tangential force of the three milling cutters, and the influence of geometric structure parameters on radial force and tangential force was different. Compared with the SD milling cutter, the change of pitch and helix resulted in the increase of radial and tangential forces, the pitch change led to the radial force being larger than the tangential force, and the helix change led to the radial force being smaller than the tangential force.
\end{abstract}

\section{Introduction}

Titanium alloys have been widely used in the aerospace, automotive, biomedical and other manufacturing industries because of their good strength-to-weight ratio, high strength and toughness, excellent corrosion resistance etc. [1-4]. However, some material characteristics of titanium alloy such as low thermal conductivity, low elastic modulus and high chemical activity etc., can increase the machining difficulty, and impair the parts qualities [5].

Milling process is widely used in machining processes for aeronautical, aerospace, die, and automobile components etc. Cutting force has a great influence on workpiece precision, surface quality, cutting system vibration, cutting power and tool life, especially when the milling cutter has a complex geometry in machining processes [6]. The cutting forces are influenced by several factors, such as tool geometry, properties of the workpiece material, cutting conditions, etc. [7], cause deflections in the cutting system by tool-workpiece-machine [8], which cause significant geometrical errors in the machined workpiece [9]. These errors are particularly important when a high tool length/diameter ratio is used, when the inclination of the machined surface is high and when tool wear is significant [10]. Cutting forces cause vibrations in machining process [11], the vibrations occur when the damping capacity of the tool-workpiece-machine system is insufficient to absorb the energy transmitted by the cutting [12]. Several authors argued that the workpiece surface quality could be improved by preventing chattering $[13,14]$. Many scholars studied on reducing vibration by changing the geometry of milling cutters. Huang et al. $[15,16]$ investigated the cutting forces by the analysis of

\footnotetext{
${ }^{\text {a }}$ Corresponding author : wychen@buaa.edu.cn
} 
time domain and frequency domain in side milling of titanium alloy TC4, the results showed that vibration reduction effect of the VP milling cutter was more obvious than SD milling cutter, the radial forces of VP milling cutter were the minimum compared with SD and VP milling cutter. Wang et al. [17] studied the cutting stability of VP and VH milling cutter, it was found that the VP and VH milling cutter could obtain larger stable cutting area than uniform pitch and uniform helix milling cutter, and the effect of suppressing chatter of VP and VH milling cutter was obviously.

In summary, cutting forces can cause the vibration of cutting system, changing the geometric structure parameters of milling cutter is an effective method to reduce the vibration and improve the quality of machined surface. In fact, the published literatures are rarely in relation to machining high strength titanium alloy TB6 with vibration-free milling cutter.

This study will investigate the cutting forces in cutting titanium alloy TB6 with vibration-free milling cutter (VP and VH milling cutter) and the SD milling cutter, analyze the influence of cutting parameters and geometric structure parameters of milling cutter on cutting forces.

\section{Experimental design}

Titanium alloy TB6 was machined with VH, VP and SD milling cutter in the experiment. The nominal chemical composition of TB6 is shown in Table 1, and the mechanical properties at room temperature of TB6 were shown in Table 2. The geometric structure parameters of the three milling cutters were shown in Table 3.

Table 1. Chemical composition of TB6 (mass fraction, \%)

\begin{tabular}{|c|c|c|c|c|c|c|c|c|}
\hline Element & $\mathbf{A l}$ & $\mathbf{V}$ & $\mathbf{F e}$ & $\mathbf{C}$ & $\mathbf{O}$ & $\mathbf{N}$ & $\mathbf{H}$ & $\mathbf{T i}$ \\
\hline $\mathrm{Wt} \%$ & 3.15 & 10.5 & 2.1 & 0.02 & 0.10 & 0.03 & 0.002 & Balance \\
\hline
\end{tabular}

Table 2. Mechanical properties of TB6 at room temperature

\begin{tabular}{|c|c|c|c|c|c|}
\hline $\begin{array}{c}\text { Tensile strength } \\
\text { (MPa) }\end{array}$ & $\begin{array}{c}\text { Yield Strength } \\
\text { (MPa) }\end{array}$ & $\begin{array}{c}\text { Elastic modulus } \\
(\mathbf{G P a})\end{array}$ & $\begin{array}{c}\text { Elongating } \\
\mathbf{( \% )}\end{array}$ & $\begin{array}{c}\text { Hardness } \\
(\mathbf{H V})\end{array}$ & $\begin{array}{c}\text { Fracture toughness } \\
(\mathbf{M P a} \cdot \sqrt{\mathbf{m}})\end{array}$ \\
\hline 1105 & 1035 & 106 & $4 \sim 10$ & $>375$ & $\geq 60$ \\
\hline
\end{tabular}

Table 3. Geometry structure parameters of three kinds of milling cutter

\begin{tabular}{|c|c|c|c|c|c|c|}
\hline Milling cutter & Blade number & $\begin{array}{c}\text { Helix angle } \\
\mathbf{( d e g})\end{array}$ & $\begin{array}{c}\text { Tooth pitch } \\
\mathbf{( d e g})\end{array}$ & $\begin{array}{c}\text { Blade length } \\
\mathbf{( m m})\end{array}$ & $\begin{array}{c}\text { Diameter } \\
(\mathbf{m m})\end{array}$ & $\begin{array}{c}\text { Tool length } \\
(\mathbf{m m})\end{array}$ \\
\hline SD & 4 & 45 & 90 & 25 & 10 & 72 \\
\hline VH & 4 & 41,45 & 85,95 & 25 & 10 & 72 \\
\hline VP & 4 & 45 & 86,94 & 25 & 10 & 72 \\
\hline
\end{tabular}

The three types of milling cutters had the same geometric structure parameters except the helix angle and tooth pitch. The cross section of three types of milling cutters was shown in Figure 1.
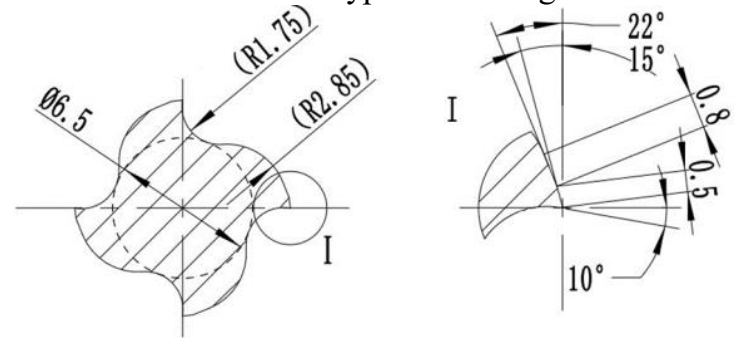
Figure 1. Cross section of three types of milling cutters (The unit of length is $\mathrm{mm}$ )

The three types of mill cutter were all carbide cutters. The VH and VP end mills had no deposited coating and SD end mill was coated with TiAlN.

The cutting parameters were listed in Table 4 and the cutting system coordinates used were shown in figure 2. The workpiece was solid block of $115 \mathrm{~mm} \times 70 \mathrm{~mm} \times 70 \mathrm{~mm}$ and the milling cutters' hang out was all $40 \mathrm{~mm}$. The cutting experiments were carried out on a five-axis CNC machine center (XKR50A) under down milling and dry machining condition. The cutting forces were measured with dynamometer (KISTLER 9123C).

Table 4. Cutting parameters of milling experiment

\begin{tabular}{|c|c|c|c|c|c|}
\hline Test number & $\begin{array}{c}\text { Cutting speed } \\
\qquad(\mathrm{m} / \mathrm{min})\end{array}$ & $\begin{array}{c}\text { Feed per tooth } \\
\qquad(\mathrm{mm} / \mathrm{z})\end{array}$ & $\begin{array}{l}\text { Axial depth } \\
\quad(\mathrm{mm})\end{array}$ & $\begin{array}{l}\text { Radial depth } \\
\text { (mm) }\end{array}$ & Milling cutter \\
\hline 1 & 20 & 0.04 & 5 & 1 & \multirow{4}{*}{ VH } \\
\hline 2 & 20 & 0.06 & 5 & 1 & \\
\hline 3 & 30 & 0.04 & 5 & 1 & \\
\hline 4 & 30 & 0.06 & 5 & 1 & \\
\hline 5 & 20 & 0.04 & 5 & 1 & \multirow{4}{*}{ VP } \\
\hline 6 & 20 & 0.06 & 5 & 1 & \\
\hline 7 & 30 & 0.04 & 5 & 1 & \\
\hline 8 & 30 & 0.06 & 5 & 1 & \\
\hline 9 & 20 & 0.04 & 5 & 1 & \multirow{4}{*}{ SD } \\
\hline 10 & 20 & 0.06 & 5 & 1 & \\
\hline 11 & 30 & 0.04 & 5 & 1 & \\
\hline 12 & 30 & 0.06 & 5 & 1 & \\
\hline
\end{tabular}

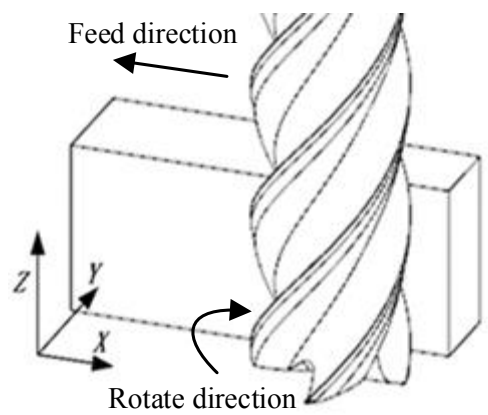

Figure 2. Cutting system coordinates

\section{Test results and analysis}


Figure 3(a) showed the change of average radial cutting forces with cutting parameters within $2 \mathrm{~s}$ of stable cutting time of three kinds of milling cutter. As shown in this figure, the radial forces of three kinds of milling cutter increase with the increase of feed, the radial forces of VP and SD milling cutters increase with the cutting speed increasing, but the radial forces of the VH milling cutter decrease with the cutting speed increasing. Under the same cutting parameters, compared with the radial forces of three kinds of milling cutter, it was found that the radial force of the VP milling cutter was the largest, the radial force of the VH milling cutter was the second, and the radial force of the SD milling cutter was the smallest. This phenomenon was different from that in milling titanium alloy TC4. Vibration-free milling cutter and standard milling cutter were used to machine titanium alloy TC4 under dry machining, side milling and down milling conditions. It was found that the radial force of the VH milling cutter was the largest, the radial force of the SD milling cutter was the second, and the radial force of the VP milling cutter was the smallest [16]. Different titanium alloy materials used to machine may be the cause of these differences.

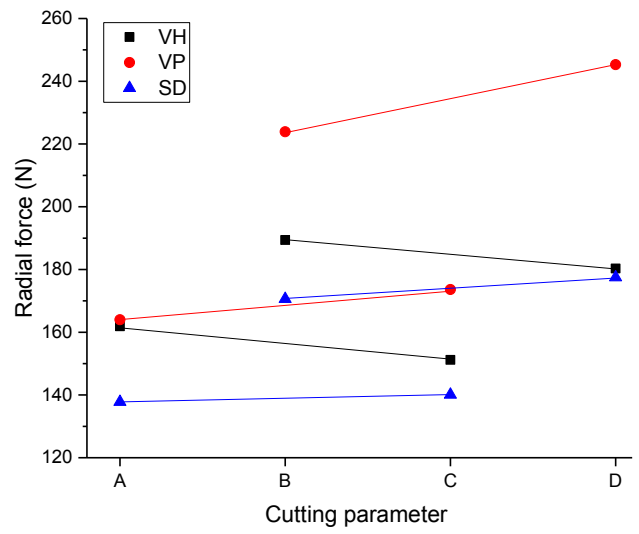

(a) Average radial cutting forces

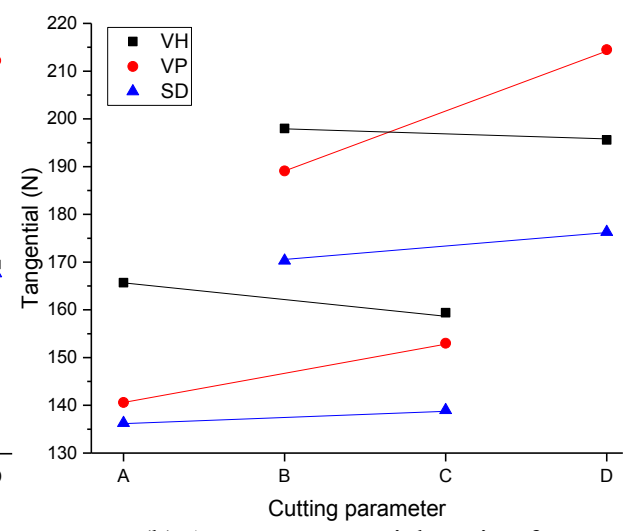

(b) Average tangential cutting forces

Figure 3. Average radial cutting and tangential cutting forces of three kinds of milling cutter with the change of cutting parameters $\mathrm{A}: \mathrm{V}=20 \mathrm{~m} / \mathrm{min}, \mathrm{f}=0.04 \mathrm{~mm} / \mathrm{z} ; \mathrm{B}: \mathrm{V}=20 \mathrm{~m} / \mathrm{min}, \mathrm{f}=0.06 \mathrm{~mm} / \mathrm{z} ; \mathrm{C}: \mathrm{V}=30 \mathrm{~m} / \mathrm{min}, \mathrm{f}=0.04 \mathrm{~mm} / \mathrm{z}$; $\mathrm{D}: \mathrm{V}=30 \mathrm{~m} / \mathrm{min}, \mathrm{f}=0.06 \mathrm{~mm} / \mathrm{z}$.

Figure 3(b) showed the change of average tangential cutting forces with cutting parameters within $2 \mathrm{~s}$ of stable cutting time of three kinds of milling cutter. It could be seen from this figure that the tangential forces of three kinds of milling cutter increased with the increase of feed, the tangential forces of VP and SD milling cutters increased with the cutting speed increasing, but the tangential forces of the $\mathrm{VH}$ milling cutter decreased with the cutting speed increasing. Under the same cutting parameters, compared with the tangential forces of three kinds of milling cutter, it was found that the tangential force of the VH milling cutter was the largest, the tangential force of the VP milling cutter was the second, and the tangential force of the SD milling cutter was the smallest.

According to the result of analysis based on above mentioned radial and tangential forces of the three kinds of milling cutter, it could be seen that cutting parameters had the same influence on the radial force and tangential force of the three milling cutters, and the influence of geometric structure parameters on radial force and tangential force was different. Compared with the SD milling cutter, the changes of pitch and helix resulted in the increase of radial and tangential forces, the pitch change led to the radial force being larger than the tangential force, and the helix change led to the radial force being smaller than the tangential force.

Figure 4 showed the contrast between the radial force and the tangential force. It could be seen from this figure that for the $\mathrm{VH}$ milling cutter, the radial force was less than the tangential force; for the VP milling cutter, the radial force was greater than the tangential force; for the SD milling cutter, there was little difference between the radial force and the tangential force. Compared with the SD milling cutter, the radial force was larger than the tangential force because of the change of pitch, and the radial force is smaller than the tangential force because of the change of helix. 


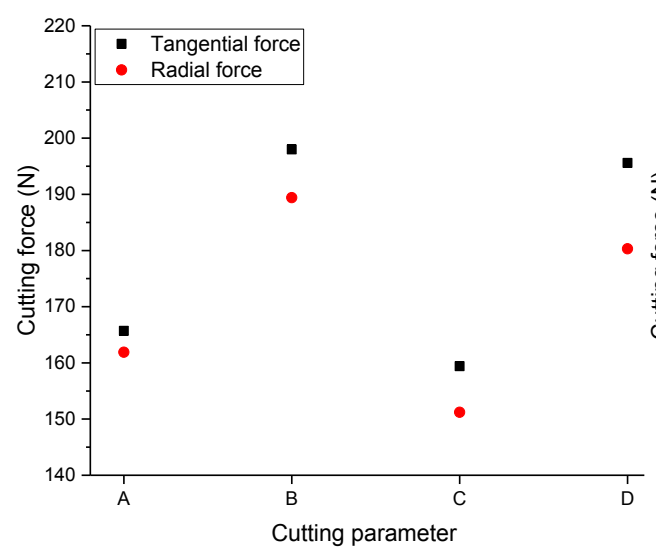

(a) VH end mill

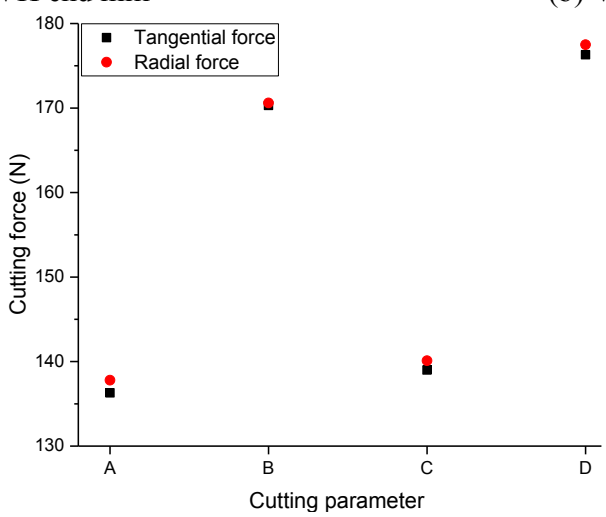

(c) SD end mill

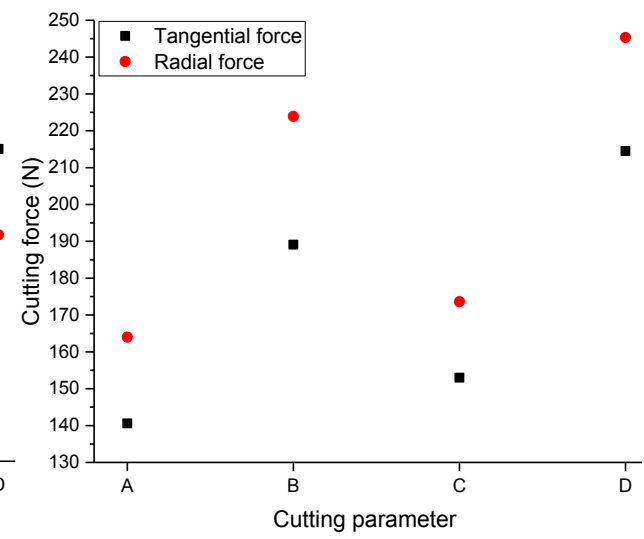

(b) VP end mill

Figure 4. Contrast between radial and tangential cutting force of three kinds of milling cutter with the change of cutting parameters $A: V=20 \mathrm{~m} / \mathrm{min}, \mathrm{f}=0.04 \mathrm{~mm} / \mathrm{z} ; \mathrm{B}: \mathrm{V}=20 \mathrm{~m} / \mathrm{min}, \mathrm{f}=0.06 \mathrm{~mm} / \mathrm{z} ; \mathrm{C}: \mathrm{V}=30 \mathrm{~m} / \mathrm{min}, \mathrm{f}=0.04 \mathrm{~mm} / \mathrm{z}$; D: $V=30 \mathrm{~m} / \mathrm{min}, \mathrm{f}=0.06 \mathrm{~mm} / \mathrm{z}$.

\section{Conclusions}

In this research, titanium alloy TB6 was dry machined using the three types of milling cutters to investigate the cutting forces. The major results are summarized as follows:

1) The influence of cutting parameters on cutting Force

The radial and tangential forces of the three kinds of milling cutter increase with the feed increasing, the radial and tangential forces of the VP and SD milling cutters increase with the increase of cutting speed, but the radial and tangential forces of the VH milling cutter decrease with the cutting speed increasing.

2) The influence of geometric structure parameters on cutting Force

Under the same cutting parameters, the radial force of the VP milling cutter is the largest, the radial force of the $\mathrm{VH}$ milling cutter is the second, and the radial force of the SD milling cutter is the smallest. The tangential force of the VH milling cutter is the largest, the tangential force of the VP milling cutter is the second, and the tangential force of the SD milling cutter is the smallest. Compared with the SD milling cutter, the radial force is larger than the tangential force because of the change of pitch, and the radial force is smaller than the tangential force because of the change of helix.

\section{References}


1. E.Ezugwu, Z.Wang, Journal of Materials Processing Technology, 68, 262-274 (1997)

2. R.Boyer, R.Briggs, Journal of Materials Engineering \& Performance, 14, 681-685 (2005)

3. M.Rahman, Z.Wang, Y.Wong, Jsme International Journal, 49,11-20 (2006)

4. D.Ulutan, T.Ozel, International Journal of Machine Tools and Manufacture, 51, 250-280 (2011)

5. A.Daymi, M.Boujelbene, A.Amara, Materials Science \& Technology, 27,387-394 (2010)

6. B.Ikua, H.Tanaka, F.Obata, Precision Engineering, 25, 266-273 (2001)

7. C.Toh, Journal of Materials Processing Technology, 152,346-356 (2004)

8. G.Kim, B.Kim, C.Chu, International Journal of Machine Tools \& Manufacture, 43, 917-924 (2003)

9. H.Erdim, I.Lazoglu, B.Ozturk, International Journal of Machine Tools and Manufacture, 46, 747757 (2006)

10. L.Lacalle, A.Lamikiz, J.Sánchez, Journal of Materials Processing Technology, 123, 292-302 (2002)

11. M.Polli, Análise da estabilidade dinâmica do processo de fresamento a altas velocidades de corte (Ph.D. Thesis, Federal University of Santa Catarina, 2005)

12. A.David, A.gapiou, S.John, Journal of Petroleum Science and Engineering, 16, 315-316 (1996)

13. H.Zhou, C.Wang, Z.Zhao, Journal of Materials Processing Technology, 207, 154-162 (2008)

14. H.Paris, G.Peigne, R.Mayer, International Journal of Machine Tools \& Manufacture, 44, 1567$1576(2004)$

15. P.Huang, J.Li, J.Sun, Journal of Cleaner Production, 67, 258-264 (2014)

16. P.Huang, J.Li, J.Sun, International Journal of Advanced Manufacturing Technology, 67, 1385$1391(2013)$

17. Y.Wang, T.Wang, Z.Yu, Shock and Vibration, 2015, 1-9 (2015) 